Research Paper:

\title{
The Life Quality of Mothers of Children With Leuke- mia and its Related Factors
}

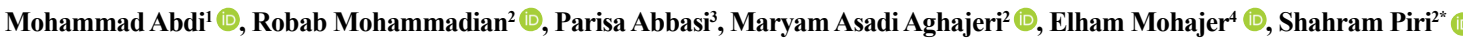 \\ 1. Department of Emergency and Critical Care, Faculty of Nursing and Midwifery, Zanjan University of Medical Sciences, Zanjan, Iran. \\ 2. Department of Nursing, Faculty of Nursing and Midwifery, Zanjan University of Medical Sciences, Zanjan, Iran. \\ 3. Registered Nurse, Baharlo Hospital, Tehran, Iran. \\ 4. Department of Nursing, Faculty of Medicine, Maragheh Branch, Islamic Azad University, Maragheh, Iran.
}

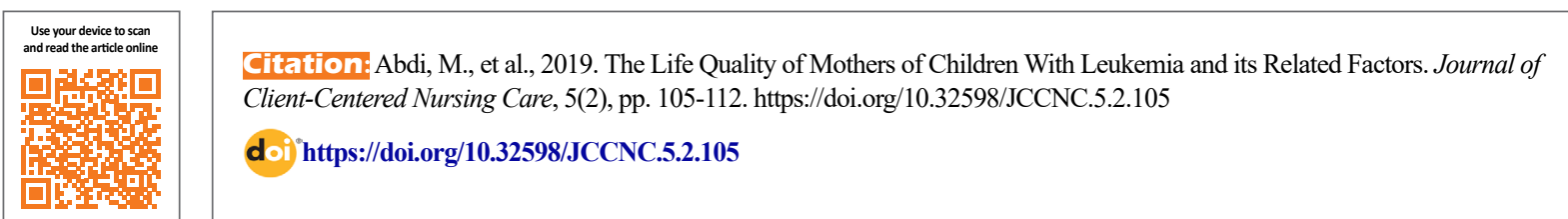

\section{(c) (1) (s)}

Article info:

Received: 17 Nov 2018

Accepted: 09 Feb 2019

Published: 01 May 2019

Keywords:

Leukemia, Children,

Mothers, Quality of life

\section{A B S T RA C T}

Background: Leukemia is the most prevalent cancer in childhood. Mothers are closer to these children than anyone else and play a vital role in caring for them; therefore, studying their life quality is necessary. This study aimed to determine the life quality of mothers of children with leukemia and its related factors.

Methods: This descriptive cross-sectional study was conducted in 2017. A total of 150 mothers of children with leukemia referring to the blood clinic and hematologic ward of Tabriz Children's Hospital were recruited. The samples were selected by convenience sampling method. Data were collected by the World Health Organization Quality of Life (WHOQOL_BREF) and analyzed by t-test, Analysis of Variance (ANOVA) and Pearson's correlation coefficient in SPSS.

Results: The Mean \pm SD score of the mothers' total quality of life was $68.28 \pm 19.77$. The educational level and occupational status of the mothers and their age were significantly associated with their life quality $(\mathrm{P}<0.05)$. Additionally, there were significant relationships between the mothers' quality of life and parents' income, family collaboration, satisfaction with their social status, and satisfaction with marital life $(\mathrm{P}=0001)$.

Conclusion: Mothers of children with leukemia have a low quality of life, and some of their socio-demographic factors could have a significant effect on their life quality. Therefore, it is suggested that nurse managers introduce vulnerable families to support organizations through appropriate planning. It is also suggested that authorities, by adopting appropriate policies, increase the general knowledge on marital affairs.

\section{* Corresponding Author:}

Shahram Piri, Msc.

Address: Department of Nursing, Faculty of Nursing and Midwifery, Zanjan University of Medical Sciences, Zanjan, Iran.

Tel: +98 (914) 9114292

E-mail: pirishahram67@yahoo.com 


\section{Highlights}

- Mothers of children with leukemia have a low quality of life.

- The life quality of mothers with leukemia is significantly related to their educational level and occupational status.

- There is a significant relationship between the quality of life of mothers of children with leukemia and parents' income, family collaboration, satisfaction with social status, and satisfaction with marital life.

\section{Plain Language Summary}

Leukemia is the most prevalent cancer in childhood. Mothers are closer to these children than anyone else and play a vital role in caring for them. The quality of life of mothers impacts the care and support for children with leukemia. The mothers of these children have a low quality of life. The age, educational level and occupational status of the mothers are associated with their life quality. There is a relationship between quality of life of mothers and parents' income, family collaboration, satisfaction with social status and satisfaction with marital life. It is suggested that nurse managers introduce vulnerable families to support organizations through appropriate planning. Moreover, authorities, by adopting appropriate policies, could increase the general knowledge on marital affairs.

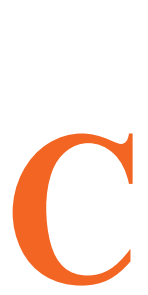

\section{Background}

ancer is a leading cause of morbidity and mortality in the world, as it has been called the new current epidemic after heart disease (Litzman et al. 2011). Cancer is the third leading cause of death after heart disease, accidents and other natural disasters in Iran, and is the second leading cause of death in third world countries (Linet et al. 2013). According to epidemiological terms, pediatric cancer refers to malignancies before the age of 15 years. Furthermore, its most common type in children is blood cancer, which accounts for about $30 \%$ of childhood cancers (DeSantis et al. 2014; Ward et al 2014). Leukemia is the most prevalent blood cancer in the world (Papastavrou, Charalambous \& Tsangari 2009). Among blood cancers, the most frequent type of leukemia is acute lymphoblastic leukemia (Rytting et al. 2017). Additionally, studies suggested that leukemia leads to many problems in patients and their families. This is due to its high morbidity and mortality rates, high diagnostic-therapeutic cost, and prolonged hospitalization (Azad et al. 2015; Braam et al. 2010; Tsimicalis et al. 2011). These problems profoundly affect the patient's family life and underlie all the biopsychosocial aspects of life. Moreover, the lack of proper care could damage family members' health (Ozer, Firat \& Bektas 2009; Shields, Kristensson-Hallström \& O'callaghan 2003).

Cancer can lead to loss of life plans in patients and their families (even single-family members), and ulti- mately decreases the quality of life of the whole family (Nemati et al. 2018). Parental quality of life plays an essential role in the process of child's treatment; any reduction in the quality of life of parents increases children's anxiety and stress, reduces focus on effective care, and harms the child during care provision (Coyne et al. 2016). Mothers are the closest person to children and their quality of life significantly impact the treatment process of children. In some studies, the effect of father and Mother's Quality Of Life (MQOL) on the treatment of children was identical; however, this effect was unequal in other studies (Kalyva \& Melonashi 2015; Sung et al. 2011; Yamazaki et al. 2005).

In various studies conducted on the life quality of the mothers of children with cancer, more attention has been paid to examining the time and duration of treatment. In addition, they considered cultural differences, the effects of symptoms and treatment on the quality of life and indicators of the disease; however, less attention has been paid to the income of parents, sociooccupational status, and satisfaction with marital life. These factors can significantly affect the quality of life of parents (Eiser, Eiser \& Stride 2005; Litzelman et al. 2011; Nemati et al. 2018).

The MQOL is affected by various socioeconomic and cultural factors. Moreover, decreased MQOL majorly influences the quality of life of children with leukemia and even delays the treatment process of these patients (Yagc-Küpeli et al. 2012; Zareifar et al. 2012). 
Some studies have suggested that the life quality of the mothers of these children may be affected by the interventions of healthcare providers (Kazak \& Meadows 2013; Watt et al. 2013). By identifying vulnerable families and referring them to supportive resources, such as social workers, insurance companies, public institutions, and governmental organizations, nurses can create mental relaxation in the patients' family. They could also play a key role in improving the quality of life of patients and their families (Lindvall et al. 2014; Linet et al. 2013; Weaver et al. 2016).

The socio-economic burden of this disease and limited studies on family-related factors that affect the life quality of the mothers of children with leukemia are essential. Thus, this study aimed to assess the life quality of the mothers of children with leukemia and its related factors in the hematology clinic and hematologic ward of Tabriz children's hospital.

\section{Materials and Methods}

This was a descriptive cross-sectional study. The study population included the mothers of children aged 1 to 14 years with leukemia. The mothers were recruited by convenience sampling method among the patients referring to the hematology clinic and hematology ward of Tabriz Children's Hospital affiliated to Tabriz University of Medical Sciences, in 2017.

To determine the sample size, a pilot study was conducted on 30 mothers. In this study, the Mean \pm SD quality of life of the mothers was $67.32 \pm 15.64$. Considering the formula $n=$ $\frac{\delta^{2} \cdot \mathrm{z}^{2}}{\mathrm{~d}^{2}}, \mathrm{~d}=0.04, \mathrm{z}=1.96$, the sample size was estimated as 148 ; however, for more precision and considering the possibility of attrition, 180 subjects were included in the study. In the course of the research, 30 subjects discontinued participation. The research was eventually conducted with the participation of 150 mothers. The instruments used in this study were a socio-demographic questionnaire and the World Health Organization Quality of Life questionnaire (WHOQOL_BREF).

The socio-demographic questionnaire included information on mother's age, level of education, age of the sick child and four questions in 5 items (very low, low, moderate, high and very high) about parent's income, family collaboration, satisfaction with their social status and marital life. For more precision, the questionnaire was completed by interviewing the parents.

The second part of the questionnaire examined the quality of life of parents of children with chronic diseases, including cancer. The World Health Organiza- tion commissioned a team to build a questionnaire for coherence in research and quality of life assessment. The result of this group work was a quality of life questionnaire with 100 questions (Group 1998). A few years later, a 26-item questionnaire was prepared for the ease of use (Nejat et al. 2006). The questionnaire examines the quality of life of parents in the aspects of physical health (questions 3-4-10-15-16-17-18), mental health (questions 5-6-7-11-19-26), social relationships (questions 20-21-22), and environmental health (questions 8-9-12-13-14-23-24-25).

Each item is answered on a 5-point Likert-type scale, including not at all, slightly, moderate, very much, maximum, which are assigned a score of 1 to 5, respectively. There are several methods for scoring this questionnaire. In this section, after considering the faculty members' viewpoints, we examined the mean scores of the dimensions of quality of life and the total score. Higher scores denote a higher quality of life. This questionnaire has been validated in various studies and has high reliability (Gupta et al. 2008; Thakar et al. 2009). Initially, the content and face validity of the Persian version of the questionnaire was assessed by 10 nursing and oncology faculty members; the obtained content validity ratio was $>0.68$, and content validity index was $>0.78$. The internal consistency of the questionnaire was confirmed by Cronbach's alpha, and it was $>0.75$.

The collected data were entered SPSS V. 20. Then, the data normalization was determined using the Kolmogorov-Smirnov test. Chi-squared test was used to compare the quality of life with qualitative factors, such as marital status. Moreover, Analysis of Variance (ANOVA) was used to compare the quality of life with several factors. Pearson's correlation coefficient was used to examine the correlation between the quality of life with parent's income, family collaboration, satisfaction with social status, and satisfaction with marital life.

\section{Results}

In total, 150 mothers of children with leukemia participated in this study. The Mean $\pm \mathrm{SD}$ age of the mothers was $31.39 \pm 3.79$ years. The Mean \pm SD score of MQOL was $68.28 \pm 19.77$. Total MQOL and its dimensions are presented in Table 1. There was a significant relationship between MQOL and the samples' socio-demographic characteristics, except age $(\mathrm{P}=0.27)$. Therefore, higher educational level and employment increase the MQOL $(\mathrm{P}<0.05)$ (Table 2). Additionally, there was a significant relationship between MQOL and the parents' income, 
Table 1. The Mean \pm SD score of life quality of the mothers of children with leukemia

\begin{tabular}{ccc}
\hline Subscales of the Quality of Life & Score's Range & Mean \pm SD \\
\hline Physical health & $7-35$ & $18.50 \pm 5.11$ \\
Mental health & $6-30$ & $15.25 \pm 5.28$ \\
Social relationship & $3-15$ & $8.04 \pm 3.30$ \\
Environmental health & $8-40$ & $25.86 \pm 6.31$ \\
\hline The total mean score of life quality & $26-130$ & $68.28 \pm 19.77$ \\
\hline
\end{tabular}

family cooperation, satisfaction with social status, and satisfaction with marital life $(\mathrm{P}=0.001)$ (Table 3$)$.

\section{Discussion}

This study determined the life quality of the mothers of children with leukemia and its related factors. Study findings suggested that the quality of life reported by the mothers was less than the average. The obtained data also revealed that nearly $80 \%$ of families participating in this study experienced severe conflicts in marital relationships and reported family performance as undesirable.
Khanjari et al. (2013) conducted a descriptive study to assess the quality of life of parents of children with leukemia in hospitals affiliated to Tehran University of Medical Sciences. Their study results indicated that the mean score of quality of life of their studied subjects was less than $50 \%$ of the total quality of life score. This finding was consistent with the present study. The main instrument of their research was the Persian Quality of Life (P-CQOLC) questionnaire of the cancer patients caregivers; however, the current study used the WHO Quality of Life Questionnaire (WHOQOL_BREF). Despite the different aspects of these two instruments, the overall result of both studies was the same. The reason for this

Table 2. Relationship between the mothers' life quality and their demographic characteristics

\begin{tabular}{|c|c|c|c|c|}
\hline \multirow{2}{*}{\multicolumn{2}{|c|}{ Demographic Features }} & \multicolumn{2}{|c|}{ Quality of Life } & \multirow{2}{*}{ Value } \\
\hline & & No. (\%) & Mean士SD & \\
\hline \multirow{2}{*}{$\begin{array}{l}\text { Marital status } \\
\text { Married }\end{array}$} & Divorced & $29(19.4)$ & $81.45 \pm 31.33$ & \multirow{2}{*}{$P=0.001$} \\
\hline & 121 & $80.6(66.22)$ & $66.29 \pm 16.09$ & \\
\hline \multirow{4}{*}{ Education } & $\begin{array}{l}\text { Elementary } \\
\text { school }\end{array}$ & $44(29.4)$ & $59.57 \pm 16.72$ & \multirow{4}{*}{$\begin{array}{l}P=0.001 \\
F=10.41\end{array}$} \\
\hline & $\begin{array}{l}\text { Secondary } \\
\text { school }\end{array}$ & $25(16.6)$ & $70.38 \pm 19.75$ & \\
\hline & $\begin{array}{l}\text { High school } \\
\text { (Diploma) }\end{array}$ & $57(38)$ & $66.64 \pm 12.70$ & \\
\hline & $\begin{array}{l}\text { University } \\
\text { degre }\end{array}$ & $24(16)$ & $87.75 \pm 27.08$ & \\
\hline \multirow{3}{*}{ Occupational status } & Housewife & $106(70.6)$ & $65.35 \pm 16.42$ & \multirow{3}{*}{$\begin{array}{l}P=0.001 \\
F=21.31\end{array}$} \\
\hline & $\begin{array}{l}\text { University } \\
\text { student }\end{array}$ & $22(14.7)$ & $81.101 \pm 26.80$ & \\
\hline & Employee & $22(14.7)$ & $75.27 \pm 17.70$ & \\
\hline \multirow{4}{*}{ Age, $y$} & $<20$ & $5(3.3)$ & $61.32 \pm 12.08$ & \multirow{4}{*}{$P=0.27$} \\
\hline & $20-30$ & $52(34.6)$ & $65.35 \pm 15.32$ & \\
\hline & $30-40$ & $58(38.7)$ & $66.23 \pm 26.81$ & \\
\hline & $>40$ & 35 (23.4) & $68.34 \pm 18.66$ & \\
\hline
\end{tabular}


Table 3. Relationship between the mothers' quality of life and the family profile

\begin{tabular}{cccc}
\hline Variable & No. & Pearson's Correlation Coefficient & P \\
\hline Family income & 150 & 1 & $<0.001$ \\
Family collaboration & 150 & 0.940 & 0.001 \\
Satisfaction with social status & 150 & 0.870 & 0.001 \\
Satisfaction with marital life & 150 & 1 & $<0.001$ \\
\hline
\end{tabular}

overall similarity may be the reduced quality of life of mothers/parents in all explored aspects. In this study, other related factors, such as collaboration between the family, satisfaction with social status, and satisfaction with marital life, were discussed. However, these factors were overlooked by Khanjari and associates.

Yu et al (2017), conducted a cross-sectional study with the participation of 309 families of children with leukemia in three hospitals of Heilongjiang Province in China. The quality of life of the family of patients with leukemia was equal to 49.4, indicating a decrease in their quality of life, which was also consistent with the study by (Yu et al. 2017). Hongjuan study also reported that the Mean \pm SD scores of different aspects of quality of life in the 4 dimensions of life quality were $12.7 \pm 2.8$ for physical health, $12.2 \pm 12.5$ for mental health, $13.92 \pm 2.9$ for social communication, and $11.33 \pm 2.53$ for environmental health; those data were inconsistent with the reported quality of life scores in the present study. The reason for this difference may be the cultural variations between the two countries. Although the localized Quality of Life Questionnaire (WHOQOL-BREF) was used in both studies, their sample size was larger than ours. Hongjuan et al. overlooked assessing other socioeconomic factors affecting the quality of life (Yu et al. 2017).

Other studies have also reported that the quality of life of parents of children with leukemia is lower than parents of children with other cancer types (Bektas \& Ozer 2009; Tang 2009). These studies also indicated that the MQOL is lower than other members of the family. Perhaps one of the reasons for this finding is the intolerance of taking care of a child with a severe illness, like leukemia for parents and especially the mother (Goldstein et al. 2004; Kohlsdorf \& Costa Junior 2011).

Klassen et al. (2008) in a prospective study in Canada, examined the life quality of 411 parents of patients with leukemia. They observed significant relationships between the quality of life of parents of children with cancer and their income, age, and physical activity. Their findings related to the relationship between income and quality of life was consistent with the present study; however, it was inconsistent with the current study in terms of the relationship between the quality of life and age. The strong feature of their study was investigating the samples over three years. The instrument used in this study was Quality of Life questionnaire (SF-36), which is different from the instrument of the present research.

Furthermore, higher income reduces stress in parents of children with illness and improves coping with difficulties, leading to a higher quality of life (Othman et al. 2011). This result is consistent with some other studies (Mousavi, Pourfeizi \& Dastgiri 2010; Usefy et al. 2010). The life of parents of patients with low-income is associated with stress, anxiety, and obsession, which affect their quality of life. For this reason, it is suggested that governmental organizations and insurance companies support these patients more.

In this study, mothers had a low quality of life. Other studies also have emphasized the reduction of life quality of female caregivers of cancer patients. Such investigations have related this issue to the high level of stress in women, which was consistent with our findings (Cordova, Riba \& Spiegel 2017; Dardas \& Ahmad 2015).

However, Khanjari et al., in a prospective study, reviewed the quality of life of the caregivers of cancer patients with similar questionnaire. Their QOL was reported as moderate to high, which is not consistent with the present study (Khanjari et al. 2012). These different reports could be related to the studied samples; because their explored patients had breast cancer and most of them were not in the terminal stage of disease. Generally, the low MQOL can be due to the uncertainty and stress caused by the unpredictable nature of the disease, the uncertainty about the treatment and other responsibilities of mothers at home and in the community.

Researchers studied the quality of life of parents of children with leukemia and brain tumors. They conclud- 
ed that the parents' higher level of education is associated with increased quality of life, which is consistent with the current study (Litzelman et al. 2011). However, in another study in Canada, the quality of life of caregivers of a family member with cancer was evaluated by a similar questionnaire; their samples' QoL was associated with a lower educational level, which is inconsistent with the present study (Tang 2009).

In Conclusion, Mothers, as the first and most important caretakers of children with leukemia, face a variety of issues, including socioeconomic and family problems. These issues illustrate the need for comprehensive psychosocial support for the affected child's parents. Understanding parents' needs and concerns, learning coping skills by them, and their participation in social activities can help improve their quality of life.

The mothers' quality of life was poor, which may be due to many conflicts, such as family income, the level of parents' dissatisfaction with marital life, the level of education, and dissatisfaction with family cooperation. To increase their quality of life, social conflicts between families should be resolved by the responsible authorities through appropriate policies, precise planning, and holding training classes for the families and providing support from insurance organizations. It is also suggested that nurses, as the most critical pillars of care, identify vulnerable families, and introduce them to private and governmental supportive institutions.

The limitations of this research can be observed in the psychological state of participants in responding to questionnaires that were beyond the researcher's control. However, the researcher tried to reduce such limitation by creating a favorable and calm environment for the mothers while answering the questionnaires.

\section{Ethical Considerations}

\section{Compliance with ethical guidelines}

This study was approved by the Ethics Committee of Islamic Azad University of Maragheh (Code: 201.13.15.4309). The study purposes were explained to the subjects. Moreover, the study participants signed informed consents.

\section{Funding}

This research was extracted from the research project (No. 201.13.15.4309), funded by Islamic Azad Univer- sity of Maragheh, Faculty of Medicine, Department of Nursing.

\section{Authors' contributions}

Analysis and interpretation of data: Shahram Piri, Mohammad Abdi; Drafting the manuscript and revising: Mohammad Abdi.

\section{Conflict of interest}

The authors of this article do not have any conflicts of interests.

\section{Acknowledgments}

We sincerely appreciate Mr. Shahram Piri, the faculty member of the Department of Medical Sciences of the Azad University of Maragheh, and Dr. Kourosh Narimani, the student deputy of this university. We also appreciate the Head Nurse of Tabriz Pediatric Hospital, Mrs. Darabi, as well as all the mothers who participated in the study and made this research possible.

\section{References}

Azad, M., et al., 2015. Short view of leukemia diagnosis and treatment in Iran. International Journal of Hematology-Oncology and Stem Cell Research, 9(2), pp. 88-94. [PMID] [PMCID]

Bektas, H. A., \& Ozer, Z. C., 2009. Reliability and validity of the Caregiver Quality of Life Index-Cancer (CQOLC) scale in Turkish cancer caregivers. Journal of Clinical Nursing, 18(21), pp. 3003-12. [DOI:10.1111/j.1365-2702.2009.02915.x] [PMID]

Braam, K. I., et al., 2010. Design of the Quality of Life in Motion (QLIM) study: A randomized controlled trial to evaluate the effectiveness and cost-effectiveness of a combined physical exercise and psychosocial training program to improve physical fitness in children with cancer. BMC Cancer, 10, p. 624. [DOI:10.1186/1471-2407-10-624] [PMID] [PMCID]

Cordova, M. J., Riba, M. B., \& Spiegel, D., 2017. Post-traumatic stress disorder and cancer. The Lancet Psychiatry, 4(4), pp. 330-8. [DOI:10.1016/S2215-0366(17)30014-7]

Coyne, I., et al., 2016. Interventions for promoting participation in shared decision-making for children with cancer. Cochrane Database of Systematic Reviews, 1(11), pp. 1-25. [DOI:10.1002/14651858.CD008970.pub3] [PMID] [PMCID]

Dardas, L. A., \& Ahmad, M. M., 2015. Coping strategies as mediators and moderators between stress and quality of life among parents of children with autistic disorder. Stress and Health, 31(1), pp. 5-12. [DOI:10.1002/smi.2513] [PMID]

DeSantis, C. E., et al., 2014. Cancer treatment and survivorship statistics, 2014. A Cancer Journal for Clinicians, 64(4), pp. 252-71. [DOI:10.3322/caac.21235] [PMID] 
Eiser, C., Eiser, J. R., \& Stride, C. B., 2005. Quality of life in children newly diagnosed with cancer and their mothers. Health and Quality of Life Outcomes, 3, p. 29. [DOI:10.1186/1477-75253-29] [PMID] [PMCID]

Goldstein, N. E., et al., 2004. Factors associated with caregiver burden among caregivers of terminally ill patients with cancer. Journal of Palliative Care, 20(1), pp. 38-43. [DOI:10.1177/082 585970402000108] [PMID]

Group, W., 1998. Development of the World Health Organization WHOQOL-BREF quality of life assessment. Psychological Medicine, 28(3), pp. 551-8. [DOI:10.1017/S0033291798006667] [PMID]

Gupta, A., et al., 2008. Quality of life and psychological problems in patients undergoing neurological rehabilitation. Annals of Indian Academy of Neurology, 11(4), 225-30. [DOI:10.4103/09722327.44557] [PMID] [PMCID]

Kalyva, E. \& Melonashi, E., 2015. Parental perceptions of health-related quality of life of Albanian children with epilepsy. Health Psychology Research, 3(2), p. 2244. [DOI:10.4081/ hpr.2015.2244] [PMID] [PMCID]

Kazak, A. E., \& Meadows, A. T., 2013. Families of young adolescents who have survived cancer: Social-emotional adjustment, adaptability, and social support family issues in pediatric psychology. Abingdon: Routledge.

Khanjari, S., et al., 2013. [Quality of life in parent of children with leukemia and its related factors (Persian)]. Iran Journal of Nursing, 26(82), pp. 1-10.

Khanjari, S., Oskouie, F., \& Langius-Eklöf, A., 2012. Lower sense of coherence, negative religious coping, and disease severity as indicators of a decrease in quality of life in Iranian family caregivers of relatives with breast cancer during the first 6 months after diagnosis. Cancer Nursing, 35(2), pp. 148-56. [DOI:10.1097/NCC.0b013e31821f1dda] [PMID]

Klassen, A. F., et al., 2008. Impact of caring for a child with cancer on parents' health-related quality of life. Journal of Clinical Oncology, 26(36), pp. 5884-9. [DOI:10.1200/JCO.2007.15.2835] [PMID]

Kohlsdorf, M., \& Costa Junior, Á. L., 2011. Coping strategies and caregiver's anxiety in pediatric oncohematology. Psicologia, 24(2), pp. 272-80.

Lindvall, K., et al., 2014. Increased burden on caregivers of having a child with haemophilia complicated by inhibitors. Pediatric Blood \& Cancer, 61(4), pp. 706-11. [DOI:10.1002/pbc.24856] [PMID]

Linet, M. S., et al., 2013. Epidemiology and hereditary aspects of acute leukemia neoplastic diseases of the blood. Berlin: Springer. [DOI:10.1007/978-1-4614-3764-2_15]

Litzelman, K., et al., 2011. Quality of life among parents of children with cancer or brain tumors: The impact of child characteristics and parental psychosocial factors. Quality of life Research, 20(8), pp. 1261-9. [DOI:10.1007/s11136-011-9854-2] [PMID] [PMCID]

Mousavi, S. M., Pourfeizi, A., \& Dastgiri, S., 2010. Childhood cancer in Iran. Journal of Pediatric Hematology/Oncology, 32(5), pp. 376-82. [DOI:10.1097/MPH.0b013e3181e003f7] [PMID]

Nejat, S. A., et al., 2006. [The World Health Organization quality of Life (WHOQOL-BREF) questionnaire: Translation and vali- dation study of the Iranian version (Persian)]. Journal of School of Public Health and Institute of Public Health Research, 4(4), pp. $1-12$.

Nemati, S., et al., 2018. Perceptions of family caregivers of cancer patients about the challenges of caregiving: a qualitative study. Scandinavian Journal of Caring Sciences, 32(1), pp. 309-16. [DOI:10.1111/scs.12463] [PMID]

Othman, A., et al., 2011. Factors related to parental well being in children with cancer (PhD. Dissertation). London: IACSITInternal Association of Computer Science.

Ozer, Z. C., Firat, M. Z., \& Bektas, H. A., 2009. Confirmatory and exploratory factor analysis of the caregiver quality of life index-cancer with Turkish samples. Quality of life Research, 18(7), pp. 913-21. [DOI:10.1007/s11136-009-9503-1] [PMID]

Papastavrou, E., Charalambous, A., \& Tsangari, H., 2009. Exploring the other side of cancer care: The informal caregiver. European Journal of Oncology Nursing, 13(2), pp. 128-36. [DOI:10.1016/j.ejon.2009.02.003] [PMID]

Rytting, M. E., et al., 2017. Acute lymphoblastic leukemia in adolescents and young adults. Cancer, 123(13), pp. 2398-403. [DOI:10.1002/cncr.30624] [PMID]

Shields, L., Kristensson-Hallström, I., \& O'callaghan, M., 2003. An examination of the needs of parents of hospitalized children: Comparing parents' and staff's perceptions. Scandinavian Journal of Caring Sciences, 17(2), pp. 176-84. [DOI:10.1046/ j.1471-6712.2003.00215.x] [PMID]

Sung, L., et al., 2011. Quality of life during active treatment for pediatric acute lymphoblastic leukemia. International Journal of Cancer, 128(5), pp. 1213-20. [DOI:10.1002/ijc.25433] [PMID]

Tang, W. R., 2009. Hospice family caregivers' quality of life. Journal of Clinical Nursing, 18(18), pp. 2563-72. [DOI:10.1111/ j.1365-2702.2008.02753.x] [PMID]

Thakar, S., Christopher, S., \& Rajshekhar, V., 2009. Quality of life assessment after central corpectomy for cervical spondylotic myelopathy: Comparative evaluation of the 36-Item Short Form Health Survey and the World Health Organization quality of life-bref. Journal of Neurosurgery, 11(4), pp. 402-12. [DOI:10.3171/2009.4.SPINE08749] [PMID]

Tsimicalis, A., et al., 2011. The cost of childhood cancer from the family's perspective: A critical review. Pediatric Blood \& Cancer, 56(5), pp. 707-17. [DOI:10.1002/pbc.22685] [PMID]

Usefy, A., et al., 2010. Psychometric properties of the WHOQOLBREF in an Iranian adult sample. Community Mental Health Journal, 46(2), pp. 139-47. [DOI:10.1007/s10597-009-9282-8] [PMID]

Ward, E., et al., 2014. Childhood and adolescent cancer statistics, 2014. A Cancer Journal for Clinicians, 64(2), pp. 83-103. [DOI:10.3322/caac.21219] [PMID]

Watt, L., et al., 2013. Family-centred care: A qualitative study of Chinese and South Asian immigrant parents' experiences of care in paediatric oncology. Child, 39(2), pp. 185-93. [DOI:10.1111/j.1365-2214.2011.01342.x] [PMID]

Weaver, M. S., et al., 2016. Establishing psychosocial palliative care standards for children and adolescents with cancer and their families: An integrative review. Palliative Medicine, 30(3), pp. 212-23. [DOI:10.1177/0269216315583446] [PMID] [PMCID] 
Yagc-Küpeli, B., et al., 2012. Health-related quality of life in pediatric cancer survivors: A multifactorial assessment including parental factors. Journal of Pediatric Hematology/Oncology, 34(3), pp. 194-9. [DOI:10.1097/MPH.0b013e3182467f5f] [PMID]

Yamazaki, S., et al., 2005. Health-related quality of life of mothers of children with leukemia in Japan. Quality of Life Research, 14(4), pp. 1079-85. [DOI:10.1007/s11136-004-3288-z] [PMID]

Yu, H., et al., 2017. Factors associated with the quality of life of family caregivers for leukemia patients in China. Health and Quality of Life Outcomes, 15, p. 55. [DOI:10.1186/s12955-0170628-6] [PMID] [PMCID]

Zareifar, S., et al., 2012. Evaluation of health related quality of life in 6-18 years old patients with acute leukemia during chemotherapy. The Indian Journal of Pediatrics, 79(2), pp. 177-82. [DOI:10.1007/s12098-011-0483-0] [PMID] 